\title{
ORNL TNS Program: Plasma Engineering Considerations and Innovations for a Medium Field Tokamak Fusion Reactor
}

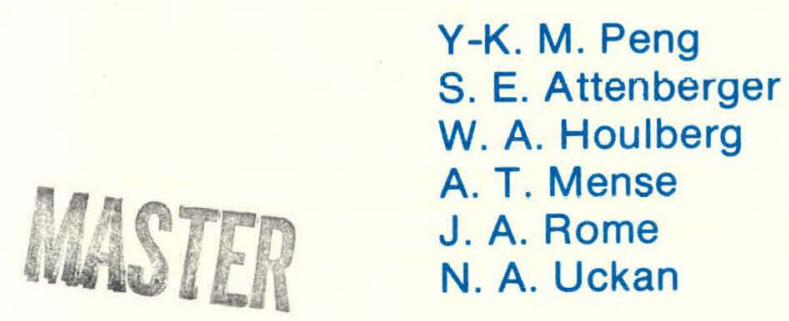




\section{DISCLAIMER}

This report was prepared as an account of work sponsored by an agency of the United States Government. Neither the United States Government nor any agency Thereof, nor any of their employees, makes any warranty, express or implied, or assumes any legal liability or responsibility for the accuracy, completeness, or usefulness of any information, apparatus, product, or process disclosed, or represents that its use would not infringe privately owned rights. Reference herein to any specific commercial product, process, or service by trade name, trademark, manufacturer, or otherwise does not necessarily constitute or imply its endorsement, recommendation, or favoring by the United States Government or any agency thereof. The views and opinions of authors expressed herein do not necessarily state or reflect those of the United States Government or any agency thereof. 


\section{DISCLAIMER}

Portions of this document may be illegible in electronic image products. Images are produced from the best available original document. 


\section{Printed in the United States of America. Available from National Technical Information Service}

U.S. Department of Commerce

5285 Port Royal Road, Springfield, Virginia 22161

Price: Printed Copy $\$ 4.50$; Microfiche $\$ 3.00$

This report was prepared as an account of work sponsored by an agency of the United States Government. Neither the United States Government nor any agency thereof, nor any of their employees, contractors, subcontractors, or their employees, makes any warranty, express or implied, nor assumes any legal liability or responsibility for any third party's use or the results of such use of any information, apparatus, product or process disclosed in this report, nor represents that its use by such third party would not infringe privately owned rights. 
Contract No. W-7405-eng-26

FUSION ENERGY DIVISION

ORNL TNS PROGRAM: PLASMA ENGINEERING CONSIDERATIONS

AND INNOVATIONS FOR A MEDIUM FIELD TOKAMAK FUSION REACTOR

Y-K. M. Peng, S. E. Attenberger, W. A. Houlberg, A. T. Mense, J. A. Rome, and N. A. Uckan

Date Published - December 1977

NOTICE This document contains information of a preliminary nature. it is subject to revision or correction and therefore does not represent a final report.

Prepared by the

Oak Ridge National Laboratory

Oak Ridge, Tennessee 37830

operated by

Union Carbide Corporation

for the

Department of Energy 


\section{THIS PAGE \\ WAS INTENTIONALLY \\ LEFT BLANK}


CONTENTS

Page

ABSTRACT

$\mathrm{v}$

1. INTRODUCTION . . . . . . . . . . . . . . . . . 1

2. TNS PLASMA ENGINEERING CONCEPTS OF A MEDIUM-FIELD

D-T REACTOR . . . . . . . . . . . . . . . . . 2

2.1 Scaling of Plasma Density with Heating Power

Density . . . . . . . . . . . . . . . . 2

2.2 1-D Multifluid Transport Estimates . . . . . . . . . 4

2.3 High $\bar{\beta}$ FCT Equilibria . . . . . . . . . . . 6

2.4 High $\bar{\beta}$ Shell-like EF Coils . . . . . . . . . . . . 6

2.5 Limits on $\bar{\beta}$ by MHD Ballooning Modes . . . . . . . . . 6

2.6 1-1/2-D Evolution of D-T Plasma in a Flux-conserving TNS Tokamak .................. 6

2.7 Neutral Beam Injection Heating Scenarios . . . . . . . 8

2.8 Self-consistent TNS Plasma Parameters . . . . . . . . 8

3. PLASMA ENGINEERING INNOVATIONS . . . . . . . . . . . 11

3.1 1-D Transport Evaluations of Pellet Fueling

Requirements - Reduced Pellet Velocity . . . . . . . 11

3.2 Keassessment of the Toroidal Field Ripple Requirements Improved Machine Access . . . . . . . . . . 12

3.3 Hybrid Equilibrium Field Colls - Reduced Engineering Difficulty and Power Supply . . . . . . . . . . . 15

3.4 Microwave Start-up - Reduced Cost of $\mathrm{OH}$ Power Supply ..................... 16

4. CONCLUSION . . . . . . . . . . . . . . . 16

ACKNOWLEDGMENTS . . . . . . . . . . . . . . . . . . 18

REFERENCES . . . . . . . . . . . . . . . . . . . 19 
THIS PAGE

WAS INTENTIONALLY

LEFT BLANK 


\begin{abstract}
Recent plasma engineering studies have ascertained a viable concept
\end{abstract} for The Next Step (TNS) reactor based on medium toroldal fields between $4 \mathrm{~T}$ and $7 \mathrm{~T}$ at the plasma center, plasma $\bar{B}$ values up to $10 \%$, and averaged densities between $0.6 \times 10^{14} \mathrm{~cm}^{-3}$ and $2.5 \times 10^{14} \mathrm{~cm}^{-3}$. Plasma engineering innovations that can substantially reduce the size, cost, and complexity of the TNS reactor have been explored and are summarized in this paper. It is shown that the previously anticipated requirement of high pellet velocities can be substantially reduced; the toroldal field (TF) ripple requirements may be relaxed to reduce the number of TF coils and improve machine access; hybrid equilibrium field (EF) coils have been shown to require building only small interior coils and to reduce the power supply required by the exterior coils; proper approaches of microwave plasma preheating may reduce the peak loop voltage for start-up by an order of magnitude.

The medium-field TNS reactor concepts and the plasma engineering innovations discussed should be applicable to other designs of tokamak reactors; some of the suggested innovations will be tested in upcoming experiments. 


\section{INTRODUCTION}

A major purpose of the plasma engineering studies in the TNS program $^{1}$ has been to explore credible ranges of physics parameters for the tokamak fusion plasma core. One of the key requirements is to establish a consistent set of physics assumptions based on recent experimental and theoretical understandings in fusion physics. Section 2 will be devoted to a discussion of the physics concepts that are employed in defining the plasma parameters in the TNS reactor.

Various tokamak reactor design studies based on a credible range of physics parameters have entailed difficult technological requirements. These include the assumed need for high speed of the pellets ( $10 \mathrm{~km} / \mathrm{sec}$ ) to fuel at the fusion plasma center for long burn, ${ }^{2}$ the poor access due to the relatively small spacings between the $T F$ coils, ${ }^{3}$ the difficulties in building and remotely maintaining the multiturn EF coils interior to the TF coils, ${ }^{3}$ and the large, $\operatorname{cost} 1 y$ pulsed power supplies ${ }^{4}$ to the ohmic heating $(\mathrm{OH})$ coils required to start the reactor plasma in full bore. These engineering and technological difficulties lend themselves to increasing the cost and complexity of the tokamak reactor.

To reduce projected cost and complexity of the reactor, another key role of the TNS plasma engineering studies is to take an innovative look at the plasma physics assumptions and approaches that have led to the technological difficulties, and further to explore new schemes to avoid them. Some of the latest studies related to the reactor problem areas just mentiunted are dlscussed in Sect. 3. As will become clear, some of the innovative solutions explored in the TNS plasma engineering studies have the potential of not only beneficially impacting the TNS reactor, but also suggesting important toplcs of study in the current and upcoming experimental and theoretical investigations. Although we use the TNS reactor as our focus for the plasma engineering studies, we believe the resulting set of plaswa parameters are equally appropriate for use in other tokamak ignition test reactors. 
2. TNS PLASMA ENGINEERING CONCEPTS OF A MEDIUM-FIELD D-T REACTOR

In choosing the range of plasma parameters for the TNS reactor, we have taken care to insure a consistent set of physics assumptions. These assumptions include: (1) the approximately linear scaling of plasma density with the heating power density, 5 (2) the inclusion of local trapped ion mode (TIM) transport coefficients ${ }^{6}$ in the 1-D transport calculations, ${ }^{7}$ (3) the use of D-shaped, high $\bar{B}$ (volume-averaged beta), flux-conserving tokamak (FCT) equilibria, , 9 (4) the use of the "shel1like" EF coils, 10 (5) the $\bar{\beta}$ limits set by magnetohydrodynamic (MHD) pressure-driven instabilities, 11,12 (6) the time-dependent evolution of the D-T fusion plasma in an FCT reactor, ${ }^{13}$ and (7) the confinement of a-particle heating that substantially eases the required neutral beam energy. 14 The bases of these concepts are briefly discussed here.

\subsection{SCALING OF PLASMA DENSITY WITH HEATING POWER DENSITY}

A recent study by Murakami et al. ${ }^{5}$ shows that the maximum densities for various ohmically heated tokamaks scale linearly with $B_{T} / R_{0}$, which in turn is roughly proportional to the plasma heating power density. In tokamaks with auxiliary heating by substantial amounts of neulral beams, higher maximum densities beyond those achievable in ohmlc discharges have been obtained.15 As F1g. 1 indicates, increasing the heating power from $420 \mathrm{~kW}$ (point A) by a factor of 1.6 (point B) in the Oak Ridge Tokamak (ORMAK) raises the density limit from $4.6 \times 10^{13} \mathrm{~cm}^{-3}$ (point A)to $7.1 \times 10^{13} \mathrm{~cm}^{-3}$ (point $B$ ), i.e., by a factor of roughly 1.6 . Fur the same higher density to be achleved only ohmically in ORMAK, the value of $\mathrm{B}_{\mathrm{T}} / \mathrm{R}_{\mathrm{O}}$ would have to be increased from $3 \mathrm{~T} / \mathrm{m}$ (point $\mathrm{A}$ ) to $5 \mathrm{~T} / \mathrm{m}$ (point $\mathrm{C}$ ), 1.e., by a factor of ruughly 1.7 .

Although values of $B_{T} / R_{0}$ above $5 \mathrm{~T} / \mathrm{m}$ in a high-field tokamak (such as Alcator ${ }^{16}$ ) can assure high densities, increased plasma heating power in a medium field tokamak with $0.5 \mathrm{~T} / \mathrm{m} \approx \mathrm{B}_{\mathrm{T}} / \mathrm{R}_{\mathrm{o}} \leqslant 2 \mathrm{~T} / \mathrm{m}$ has similar capabilities of reaching high density. For TNS, $B_{T} / R_{0}$ is assumed to be in the medium-field range with a neutral injection power $\left(P_{\text {inj }}\right)$ of i75 MW. By also using effective plasma purity control mechanisms to 


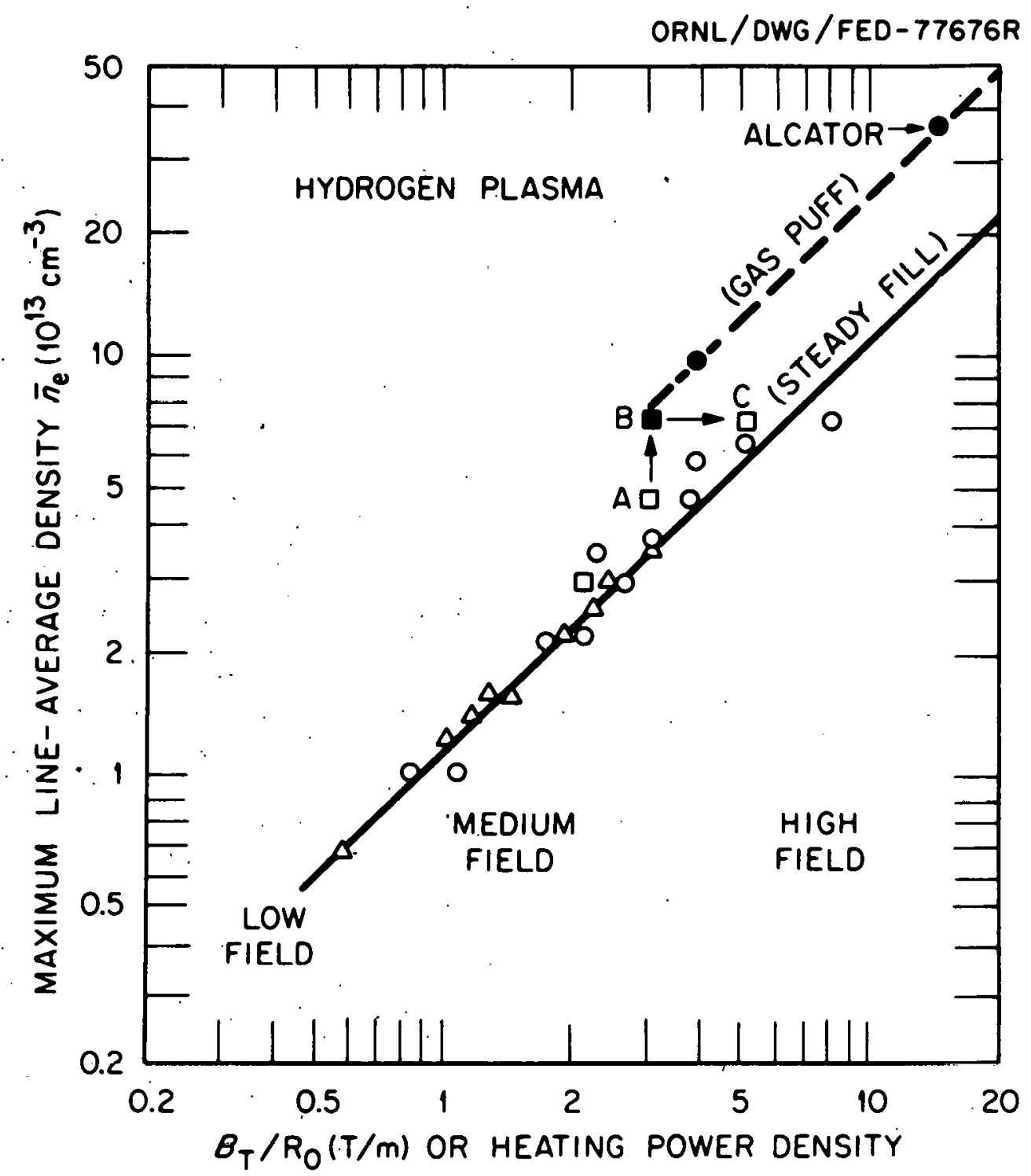

Fig. 1. Scaling of maximum line averaged densities with and without gas puffing for ORMAK and other tokamaks. Neutral beam injection allowed an increase of the density limit in OKMAK. Point A corresponds to ohmic heating power $\left(\mathrm{P}_{\mathrm{OH}}\right)$ of $420 \mathrm{~kW}$ only. Point $\mathrm{B}$ corresponds to an addition of neutral injection power $\left(P_{\text {inj }}\right)$ of $240 \mathrm{~kW}$. Point $C$ corresponds to the higher density value of the $B_{T} / R_{0}$ than point $A$ produced ohmically. 
insure $z_{\text {eff }} \lesssim 1.5$, the assumption of achieving a plasma density of at least a few times $10^{14} \mathrm{~cm}^{-3}$ in TNS is reasonable.

\subsection{1-D MULTIFLUID TRANSPORT ESTIMATES}

In a zero-dimensional (O-D) study ${ }^{17}$ based on the empirical energy confinement scaling derived from experiments in ATC, ORMAK, and Alcator, a set of reference parameters has been obtained and is shown in Table 1 . For the case with $\mathrm{K}_{\mathrm{o}}=5 \mathrm{~m}, \mathrm{a}=1.25 \mathrm{~m}, \mathrm{~b} / \mathrm{a} \simeq 1.6$, and $\mathrm{B}_{\mathrm{T}}=4.3 \mathrm{~T}$, the $\mathrm{D}-\mathrm{T}$ plasma is found to ignite at $\beta=11 \%$ using $/ 3$ MW neutrai beam infection and to burn at $\beta=15 \%$ producing $1500 \mathrm{MW}$ fusion power. When the global TIM loss rate, $\mathrm{D}_{\text {TIM }}$, is considered, it is found that a value of $\mathrm{D}_{\mathrm{TIM}} / 10$ is equivalent to the empirical scaling.

Although the use of a full $\mathrm{D}_{\mathrm{TIM}}$ loss rate may result in pessimistic estimates of the plasma performance in TNS, the use of $\mathrm{D}_{\mathrm{TIM}} / 10$. in the O-D calculations needs justification. Such a justification can be found in a recent study using a 1-D analytic model that describes the energy and particle transport in a tokamak reactor dominated by the TIM insta-

bility. 18 It is shown that the density profile solution of the transport equations leads to an equivalent global loss rate, $\left\langle\mathrm{D}_{\mathrm{TIM}}{ }\right.$, no larger than $\mathrm{D}_{\mathrm{TIM}} / 10$.

The effects of the density profile on $\left\langle\mathrm{D}_{\mathrm{TIM}}\right\rangle$ are also investigated using 1-D multifluid transport codes with pellet fueling. ${ }^{7}$ It is shown that fueling profiles peaked toward the plasma edge tend to flatten the density profile, which in turn reduces the trapped ion loss rate. 19

\subsection{HIGH $\bar{\beta}$ FCT EQUILIBRIA}

With large neutral beam powcro, the plaema le expuctud bu lieat up in a time scale much shorter than the plasma skin time. The resulting sequence of plasma equilibria then forms a family of flux-conserving equilibria. ${ }^{8}$ Calculations in a D-shaped $\mathrm{FCT}^{9}$ have produced equilibria of $\vec{\beta}$ above $20 \%$ and a safety factor up to five in TNS. Values of $\bar{\beta}$ substantially above a few percent are expected to result in high fusion power density, to permit the use of medium field, and to reduce the reactor size. 
Table 1. Typical parameters for a D-shaped, medium field TNS $\left[\mathrm{R}_{\mathrm{o}}=5 \mathrm{~m}, \mathrm{a}=1.25 \mathrm{~m},(\mathrm{~b} / \mathrm{a})=1.6, \mathrm{~B}_{\mathrm{T}}(\max )=8 \mathrm{~T}, \mathrm{~B}_{\mathrm{T}}\left(\mathrm{R}_{\mathrm{o}}\right)=4.3 \mathrm{~T}\right.$, $q_{a}=4$; higher $B_{T}$ (up to $7 \mathrm{~T}$ at $R=R_{0}$ ) results in increased margin of flexibility or reduced device size.]

\begin{tabular}{lll}
\hline & $0-\mathrm{D}$ estimates & Self-consistent parameters \\
\hline $\mathrm{I}_{\mathrm{p}}$ (ohmic) (MA) & 4.0 & 4.0 \\
$\mathrm{I}_{\mathrm{p}}$ (burn) (MA) & 6.0 & $4.5-5.5$ \\
$\mathrm{n}$ (ohmic) $\left(\mathrm{cm}^{-3}\right)$ & $0.5 \times 10^{14}$ & $0.3-0.5 \times 10^{14}$ \\
$\overline{\mathrm{n}}$ (burn) $\left(\mathrm{cm}^{-3}\right)$ & $2.2 \times 10^{14}$ & $0.6-2.5 \times 10^{14}$ \\
$\overline{\mathrm{T}}$ (ohmic) (keV) & 2 & $1.0-2.0$ \\
$\overline{\mathrm{T}}$ (ign) (keV) & 11 & $4.0-7.0$ \\
$\overline{\mathrm{T}}$ (burn) (keV) & 13 & $5.0-10$ \\
$\bar{B}$ (ign) (\%) & 11 & $3.0-5.0$ \\
$\bar{B}$ (burn) (\%) & 15 & $3.5-10$ \\
$\mathrm{C}$ (ohmic) & 0.5 & $0.14-0.96$ \\
$\mathrm{C}$ (burn) & 0.02 & $0.01-0.15$ \\
$\overline{\mathrm{n} \tau}(\mathrm{burn})\left(\mathrm{cm}^{-3} \mathrm{sec}\right)$ & $3 \times 10^{14}$ & $0.6-2.5 \times 10^{14}$ \\
$\mathrm{P}_{\mathrm{D}-\mathrm{T}} / \mathrm{V}\left(\mathrm{MW} / \mathrm{m}^{3}\right)$ & 6 & $0.4-8.0$ \\
$\mathrm{~W}_{\mathrm{L}}$ (MW/m $)$ & 3.7 & $0.3-5.0$ \\
$\mathrm{P}_{\mathrm{D}-\mathrm{T}}(\mathrm{MW})$ & 1500 & $100-2000$ \\
\hline
\end{tabular}




\subsection{HIGH $\bar{\beta}$ SHELL-LIKE EF COILS}

The characteristic configurations of the proper EF coil have been determined. It has been shown that the proper coil arrangements can either be interior 10 or exterior ${ }^{20}$ to the TF coils. As indicated in Fig. 2, either the interior or the exterior coils are divided into three groups, the coils in each group being connected in series and requiring a single power supply. It has also been demonstrated 20 that either option of the coils can maincain the plasma position and D-shape over a wide range of $\bar{B}$ values.

\subsection{LIMITS ON $\bar{\beta}$ BY MHD BALLOONING MUUES}

Although MHD equilibrium $\bar{\beta}$ above $20 \%$ with. $q_{a} \lesssim 5$ in TNS has been obtained based on the FCT approach, pressure-driven MHD instabilities are expected to limit $\bar{\beta}$ to lower values. Recent calculations ${ }^{1}$ have revealed $D$-shaped equilibria which are stable with respect to the internal ballooning modes at $\bar{\beta}$ values of $\sim 5 \%$ for TNS-like tokamaks. For a tokamak with aspect ratio equal to 2.4 , stable $\bar{\beta}$ values up to $12 \%$ have been found. 12 With shaping and profile optimizations, current estimates of stable $\bar{B}$ are between $5 \%$ and $10 \%$ for TNS.

Recent analytic ${ }^{21}$ and numerical ${ }^{22}$ ballooning modes have provided further indications that a D-shaped plasma with modest elongation and realistic current profiles provides a factor of two to three increase in stable $\bar{\beta}$ values from the circular plasmas. ${ }^{23}$ However, the $0-D$ scaling calculation has indicated that ignition and burn occur at $\bar{\beta}-11 \%$ and $15 \%$, respectively (see Table 1 ), above the estimated $\bar{\beta}$ 11mit for MDD slability.

\subsection{1-1/2-D EVOLUTION OF D-T PLASMA IN A FLUX-CONSERVING TNS TOKAMAK}

The resolution of this apparent discrepancy in $\bar{B}$ requirements lies in the effects of the density $(n)$ and temperature (T) profiles on the fusion power output. Since the D-T fusion power density is proportional to $\mathrm{n}_{\mathrm{D}} \mathrm{n}_{\mathrm{T}} \propto \mathrm{n}^{2}$ and is significant only when the local $\mathrm{T} \gtrsim 6 \mathrm{keV}$, one finds 


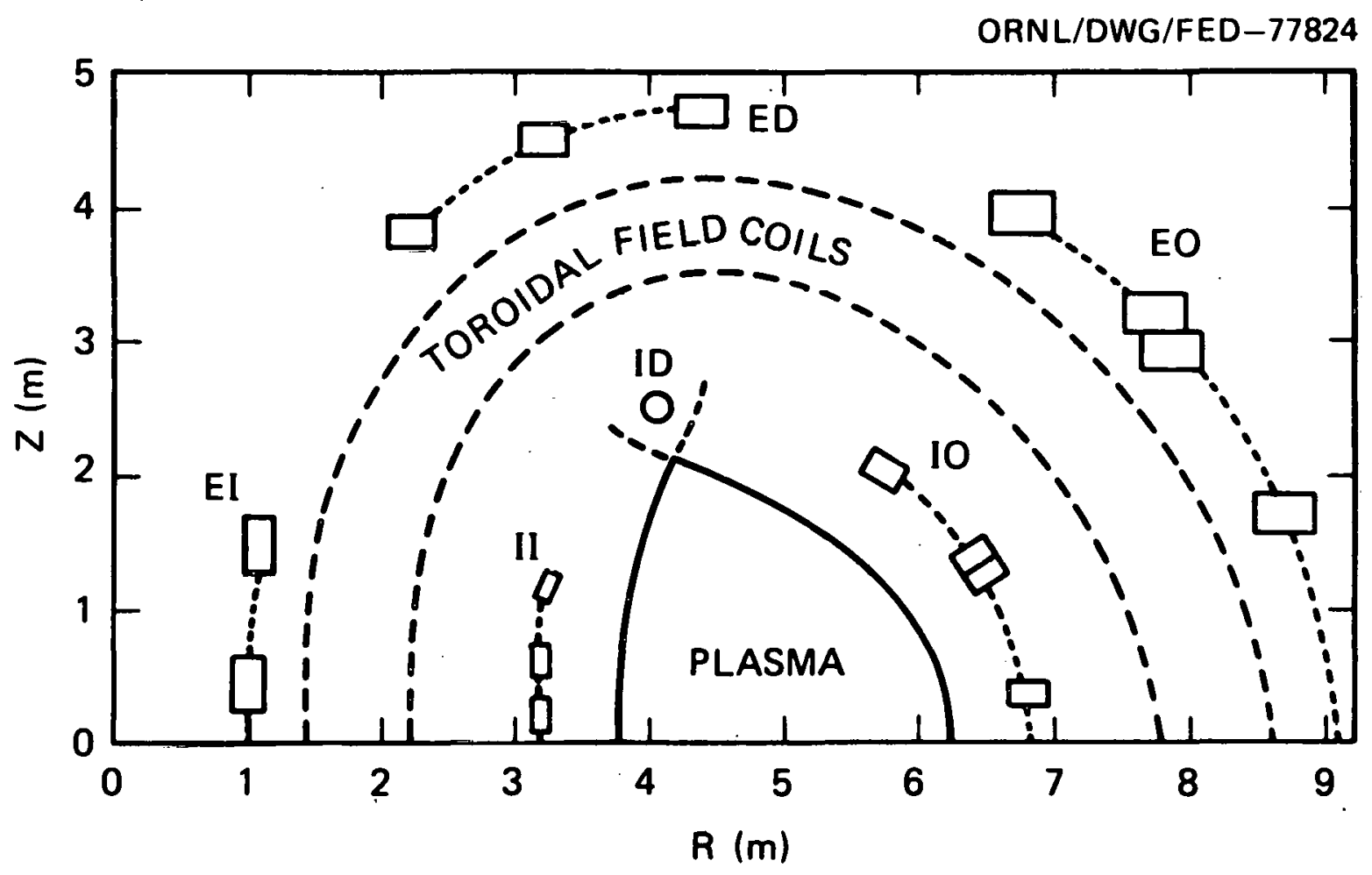

Fig, 2. Generic EF coils that are interior (II, ID, IO) or exterior (EI, ED, EO) to the TF coils. Either the interior or the exterior coils can be used alone to maintain high- $\beta$, D-shaped equilibria. The dotted lines indicate a group of coils that are connected in series and use a single power supply. Only three power supplies are needed for either the interior or the exterior set. 
that $\int d V n_{D} n_{T}\langle\sigma v(T)\rangle>>\overline{V n}_{D} \bar{n}_{T}\langle\sigma v(\bar{T})\rangle$ near ignition. The 0-D model is thus inadequate in estimating the ignition and burn requirements of TNS plasma.

The evolution of TNS plasma heated by neutral injection to ignition and burn is studied with the flux-surface averages of the particle and energy balance equations together with FCT MHD equilibria. ${ }^{13}$ It is found that the centrally peaked density and temperature profiles result in centrally localized $\alpha$-particle heating, which can exceed the injection heating when a relatively low value of $\bar{\beta}\left(i^{2} .5 \%\right)$ is reached. When $\bar{\beta}>3.0 \%$, the plasma can be considered ignited near the center to bring about an overall stedilyastate burn. $\Lambda \varepsilon$ indicated in Fig. 3, the steadystate burn can occur (assuming the empirical confinement law) with $3.5 \% \lesssim \bar{\beta} \lesssim 15 \%$ and giving $100 \mathrm{MW} \lesssim \mathrm{P}_{\mathrm{D}-\mathrm{T}} \lesssim 3000 \mathrm{MW}$ by controlling the density over the range of $0.6 \times 10^{14} \mathrm{~cm}^{-3} \leqslant \bar{n} \approx 3 \times 10^{14} \mathrm{~cm}^{-3}$.

It is seen that the ignition and burn processes in TNS can be controlled over a wide range of $\bar{\beta}$ and $P_{D-T}$ values by adjusting $\bar{n}$.

\subsection{NEUTRAL BEAM INJECTION HEATING SCENARIOS}

Because of the centralized $\alpha$-particle heating, the need for full neutral beam penetration beyond $\bar{\beta} \underline{\sim} 2.5 \%$ is eliminated (see F1E. 4). An attractive injection procedure ${ }^{14}$ emerges that starts with low density, ohmically heated plasma to facilitate initial penetration. Plasma density is increased in conjunction with the increased $\bar{\beta}$ to reduce beam penetration away frum llie plasma ccnccr, whuse significant $\alpha$-particle heating occurs. It is found llat beam cncrgy from $150 \mathrm{keV}$ to $200 \mathrm{keV}$ may be sufficient for perpendicular injection at $z_{\text {eff }} \lesssim 1.5$ in TNS.

\subsection{SELF-CONSISTENT TNS PLASMA PARAMETERS}

Based on the physics concepts discussed above, we have arrived at a set of self-consistent plasma parameters for the TNS reactor with $\mathrm{B}_{\mathrm{T}}=4.3 \mathrm{~T}$, medium-to-high density $\left(0.6 \times 10^{14} \mathrm{~cm}^{-3} \leq \mathrm{n} \leq 2.5 \times 10^{14}\right.$ $\mathrm{cm}^{-3}$ ), and high beta tokamak ( $\bar{B}$ up to $10 \%$ ) (see Table 1 ). Upcoming 
ORNL/OWG/FED-77673

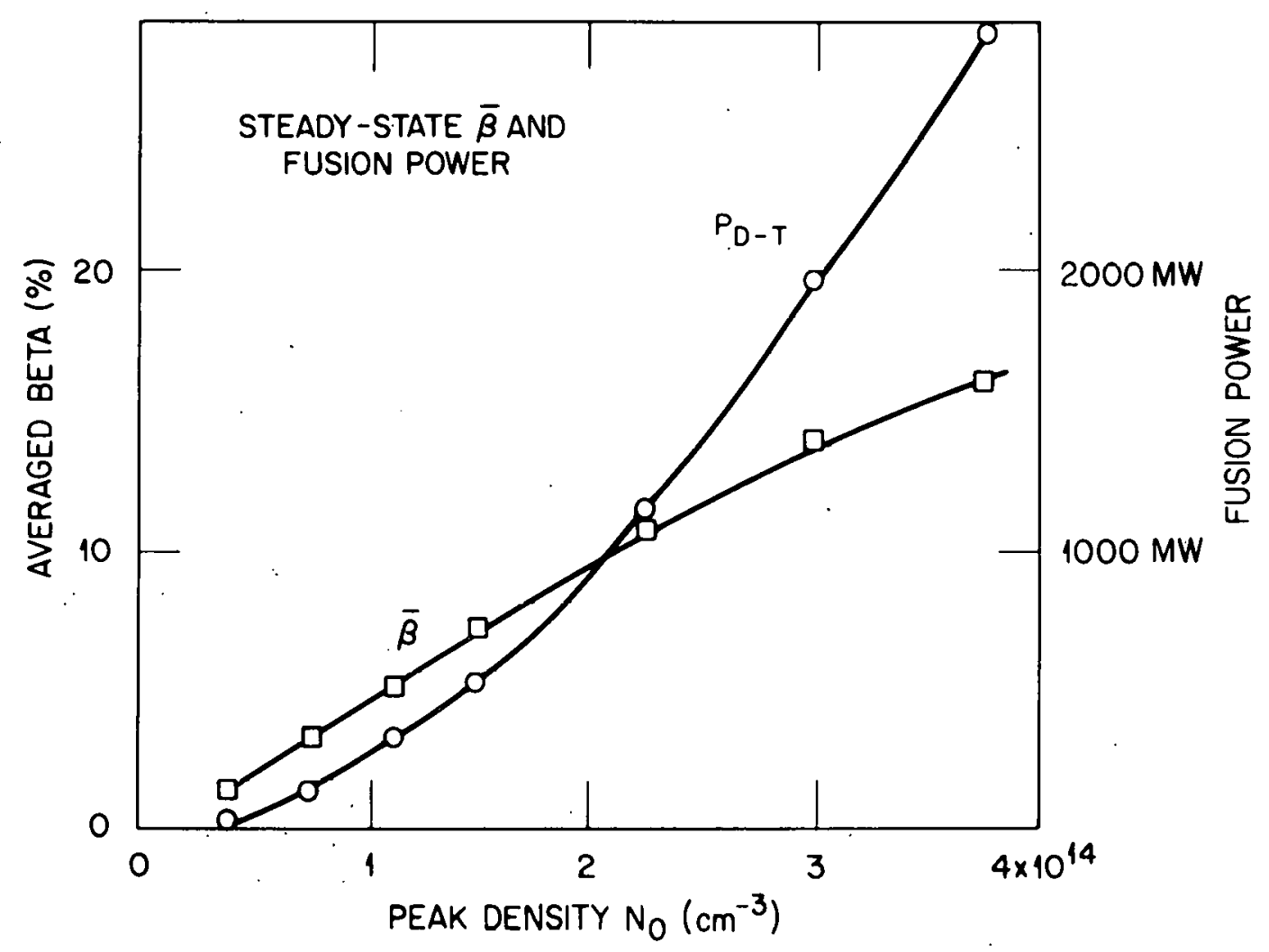

Fig. 3. The density dependence of the $\bar{\beta}$ values and fusion power $\mathrm{P}_{\mathrm{D}-\mathrm{T}}$ at the steady-state burn in TNS, assuming empirical energy confinement scaling with a plasma heat conductivity profile similar to those deduced from ORMAK observations. 
ORNL/DWG/FED $\cdot 77267$

ALPHA HEATING POWER CAN RELAX BEAM PENETRATION REQUIREMENTS
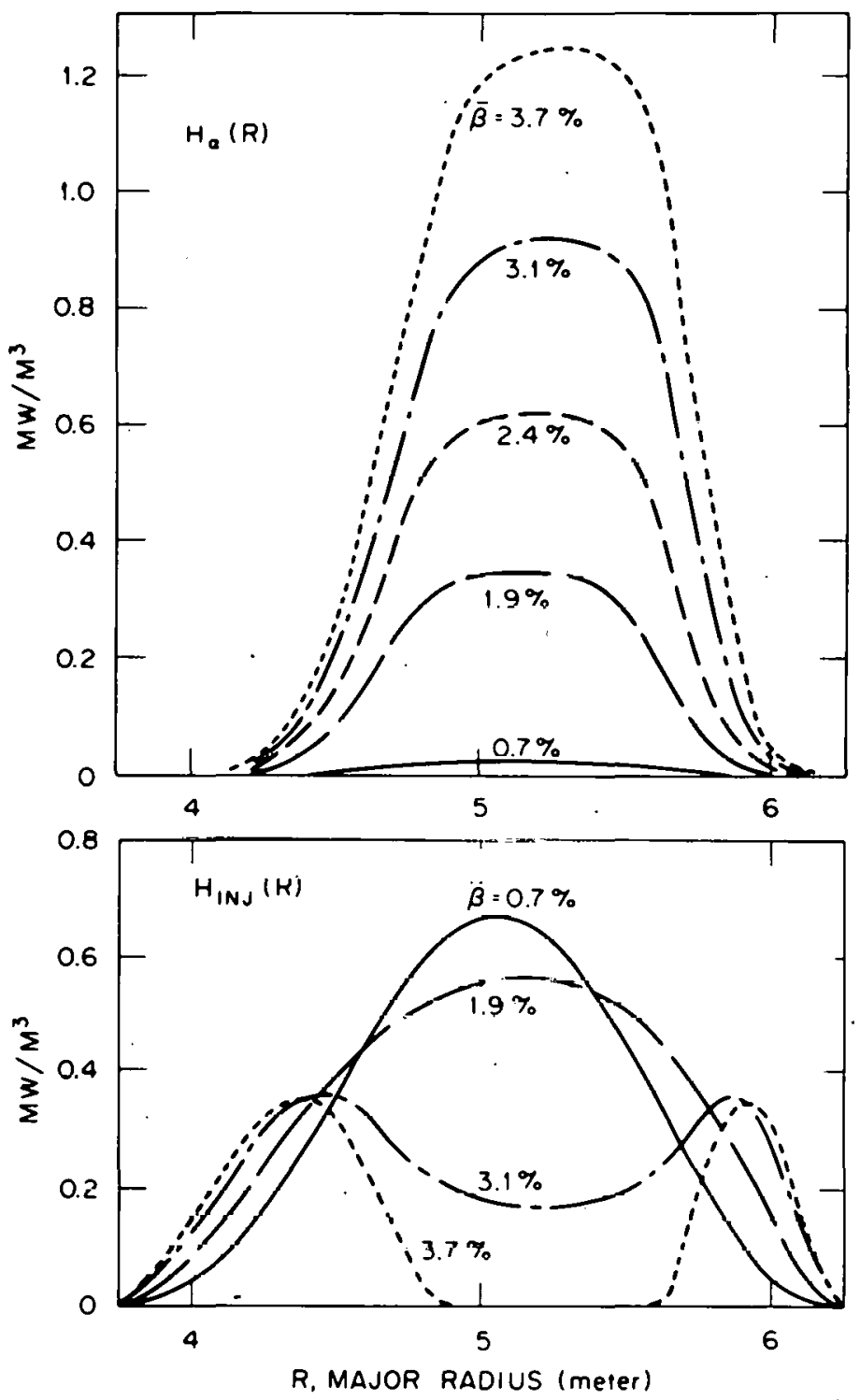

Hig. 4. Alpha-partlcle healiing and the required ncurral injection heating profiles in a sequence of FCT equilibrium in TNS form $\bar{\beta}=0.7 \%$ to $3.7 \%$. Meanwhile, the peak plasma density $\left(n_{0}\right)$ is assumed to increase from $1.2 \times 10^{14} \mathrm{~cm}^{-3}$ to $2.1 \times 10^{14} \mathrm{~cm}^{-3}$ in a linear fashion with $\bar{\beta}$. 
tokamak experiments will refine stability limits of $\bar{\beta}$ and plasma confinement scaling laws. Since $\mathrm{B}_{\mathrm{T}}=4.3 \mathrm{~T}$ is near the lower end of the medium-field strength (see Fig. 1), a large margin of reliability can be achieved in TNS by using $B_{T}=6-7 \mathrm{~T}$ with a similar device size. If the experiments indicate $\bar{\beta}$ limits and confinement scalings comparable to or more favorable than those used in this discussion, smaller TNS sizes can be considered in the future.

\section{PLASMA ENGINEERING INNOVATIONS}

The TNS reactor based on the physics parameters shown in Table 1 assumes a number of significant technological developments. Here we briefly discuss four such areas in which innovations in the plasma engineering studies have a high potential of circumventing or avoiding the advanced technological requirements. These areas cover: (1) the high speed of the pellets anticipated for fueling at the plasma center for long burn, ${ }^{2}$ (2) the relatively poor access due to the anticipated number of TF coils ${ }^{3}$ for a TF ripple less than a few percent at the outer plasma edge, (3) the difficulties in building and remotely maintaining the multiturn EF coils interior to the TF coils, ${ }^{4}$ and (4) the relatively large, costly pulsed power supplies ${ }^{4}$ to the $\mathrm{OH}$ coils required to start up the plasma current in full bore.

\subsection{1-D TRANSPORT EVALUATIONS OF PELLET FUELING REQUIREMENTS ${ }^{24}$ - REDUCED PELLET VELOCITY}

Pellet injection simulations using a discrete pellet ablation mode $1^{25}$ based on observations in ORMAK have been carried out selfconsistently with a 1-D multifluid transport code. The code uses the six-regime anomalous transport $\operatorname{model}^{6}$ together with the full neoclassical transport matrix as a reference level of losses.

We find that fueling with $2-\mathrm{mm}, 1-\mathrm{km} / \mathrm{sec}$ pellets tends to flatten the density profile over the bulk of the plasma and thus dramatically reduces the trapped particle loss rates in a fashion consistent with the analytic estimates. 18 As a result, the inclusion of the full trapped 
particle losses increases the heating power required for ignition only by a factor of two to three from the neoclassical estimates. An optimal fueling depth up to one-half the plasma minor radius also emerges ${ }^{5}$ (see Fig. 5). It appears that full penetration by pellets into the plasma may not be desirable due to the associated enhancement of the gradientdriven, trapped particle loss rates.

The requirement of high pellet velocities around $10 \mathrm{~km} / \mathrm{sec}$ as anticipated previous $1 y^{2}$ could be eased considerably. Assuming that the required depth of pellet penetration can be reduced to roughly a quarter of the minor radius, pellet veloclttes in the vicinity of $3 \mathrm{~km} / \mathrm{sec}$ may be more desirable.

\subsection{REASSESSMENT OF THE TOROTDAL FIELD RIPPLE REQUIREMENTS - IMPROVED MACHINE ACCESS}

In many tokamak designs, it is assumed that the TF ripples near the plasma edge should be lower than one percent or so to avoid any potentially deleterious effects on the plasma confinement. The implied number of TF coils in a reactor is usually around 20, which in turn has strongly limited the access ${ }^{3}$ to the plasma, the vacuum vessel, the shield, and the interior EF coils. There is strong engineering incentive to carry out a more detailed study of the ripple-induced plasma transport.

We have studied the magnetic field ripple effects with the inclusion of noncircular cross sections of the TF coils and the plasma. ${ }^{26}$ It is found that, for the typical TNS plasma shown in Table $I$ and using 20 nearly pure-tension $\mathrm{TF}$ coils with a bore of roughly $7.7 \mathrm{~m} \times 5.4 \mathrm{~m}$, Llie ripple at the D-shaped plasma edge is below one percent. ${ }^{7}$ The eslimated heat conductivity due to the ripple-trapped ions is then somewhat less than the pseudoclassical electron conduction and also the neoclassical ion conduction (see Fig. 6).

In regions where $r>a / 2$, this ripple conduction loss rate is one order of magnitude less than the empirical loss rate, which in turn is another order of magnitude less than the trapped particle loss rates. A reduced number of TF coils will then allow a ripple-induced loss rate comparable to the empirical or the trapped particle loss rates. As 
ORNL/DWG/FED-77596A

FUELING PROFILES MAY HAVE A STRONG BEARING ON HEATING POWER REQUIREMENTS (A. T. MENSE, ET AL)

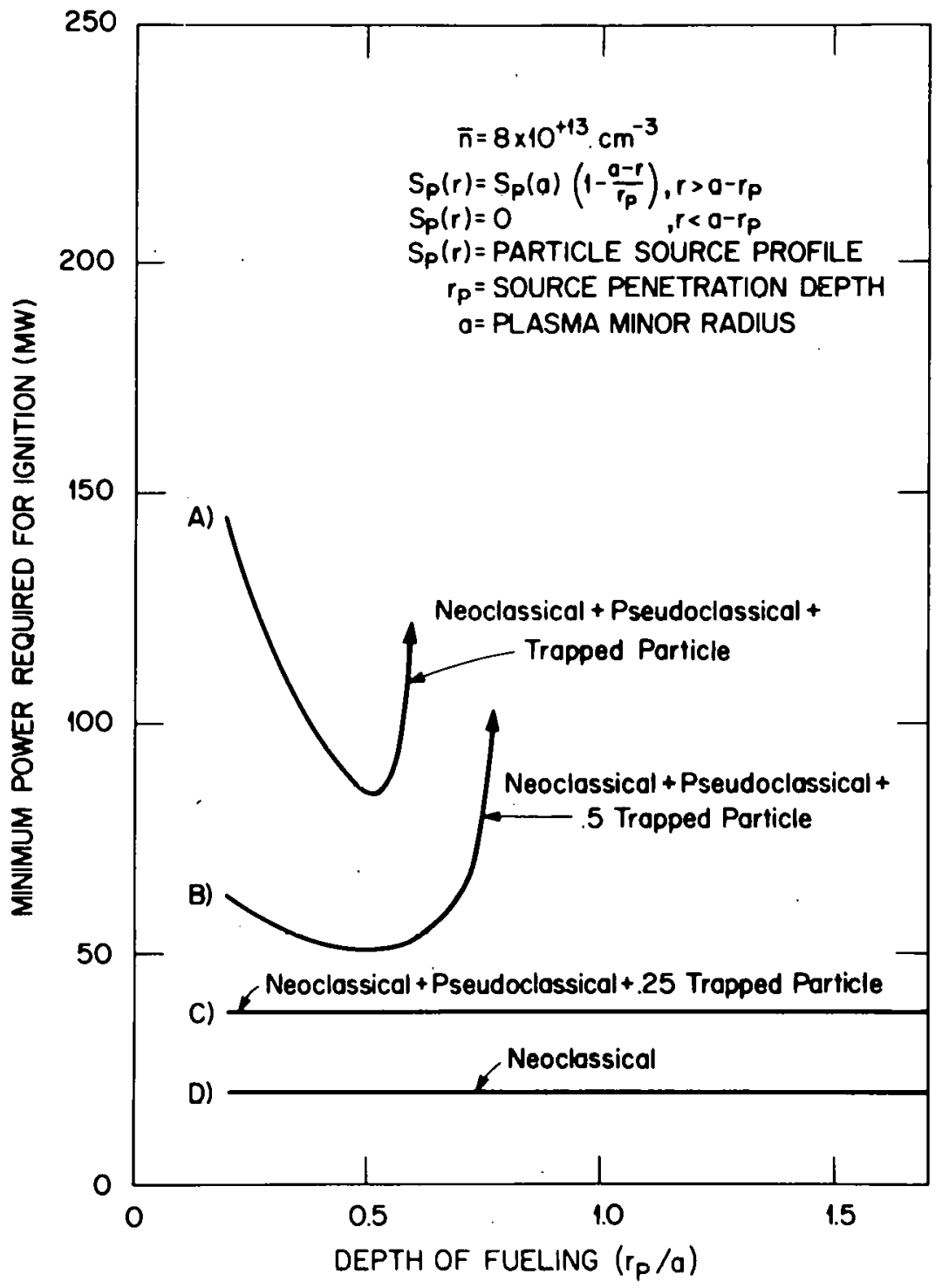

Fig. 5. The dependence of the minimum heating power (required for ignition) on the depth of fueling for various levels of trapped particle loss rates assumed in the 1-D transport calculations for TNS. 
THE ACCEPTABLE MINIMUM NUMBER OF TF COILS DEPENDS ON THE DOMINATING TRANSPORT PROCESS

ORNL/DWG/FED-77813

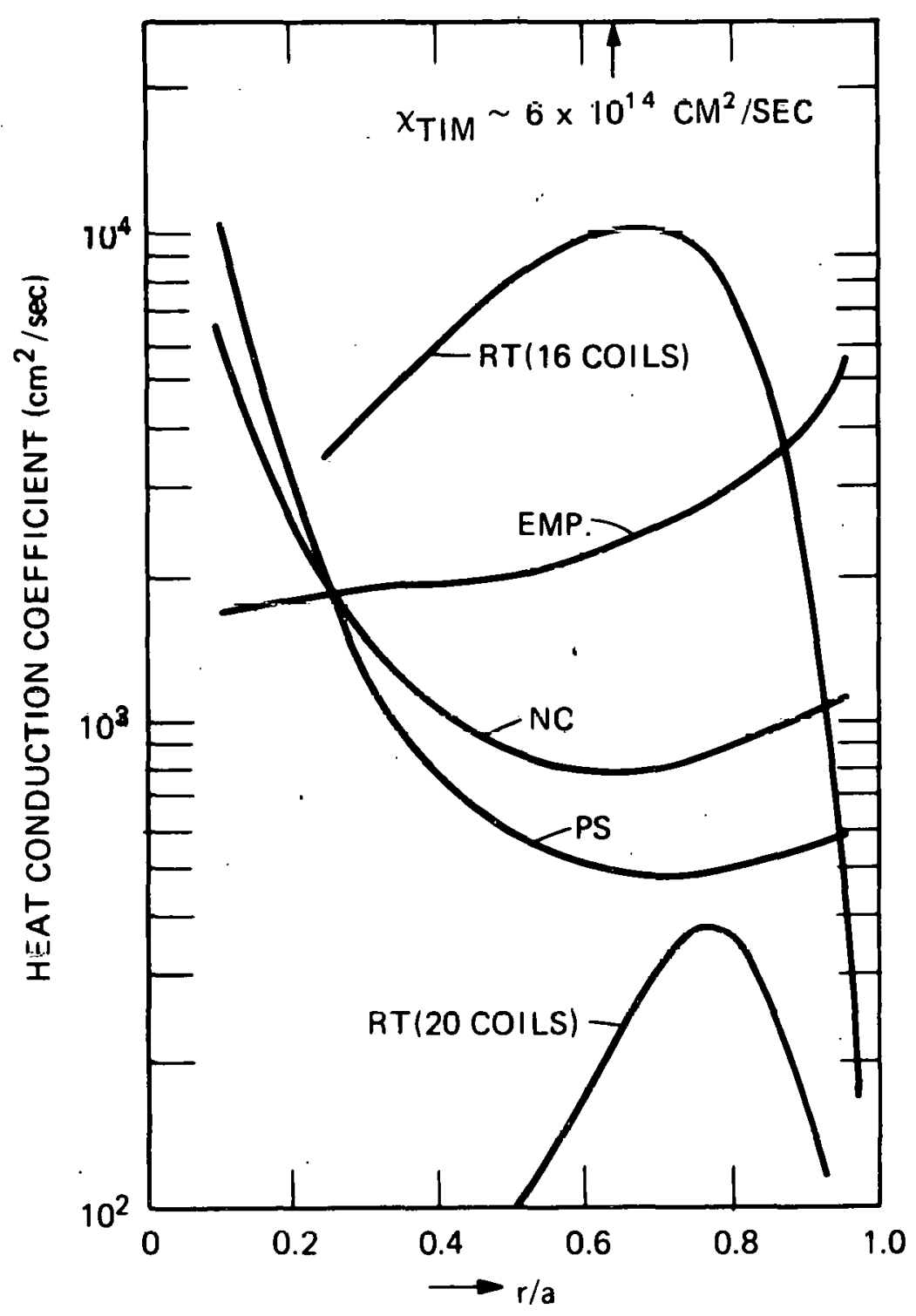

Fig. 6. Heat conduction due to ripple trapping of the ions for 20 and $16 \mathrm{TF}$ coils in TNS in comparison with the pseudoclassical, neoclassical Alcator empirical, and trapped particle coefficients. 
indicated in Fig. 6, the use of $16 \mathrm{TF}$ coils with the same bore would result in a ripple conduction coefficient that is roughly five times above the empirical coefficient and roughly six times below the TIM coefficient. Inclusion of the ripple-induced heat loss rate into the 1-D transport calculations will provide an improved assessment of the tolerable reductions in the number of $T F$ coils.

\subsection{HYBRID EQUILIBRIUM FIELD COILS - REDUCED ENGINEERING DIFFICULTY AND POWER SUPPLY ${ }^{28}$}

The interior EF coils shown in Fig. 2 are closely coupled to the plasma. If they are also arranged to mimic a conducting she11, 10 they have the advantages of requiring a relatively small power supply and minimizing the $\mathrm{OH}$ power supply during plasma start-up and rapid heating; they also contribute to stabilizing the axisymmetric modes. ${ }^{29}$ However, being about $0.5 \mathrm{~m}$ away from the plasma, they are necessarily copper coils due to the anticipated neutron heating load. Because each coil bundle carries an average ampere-turn of about $0.4 \mathrm{MA}$, multiturn coils must be used; these make them difficult to build and remotely maintain under radioactive environments.

The exterior EF coils shown in Fig. 2 largely avoid these engineering difficulties; however, they require a total power supply which is an order of magnitude above the interior coil requirements. During start-up, the exterior coils require a total of $1.2 \mathrm{GW}$ in addition to an $\mathrm{OH}$ requirement of $2.4 \mathrm{GW}$; the latter is twice the $\mathrm{OH}$ requirement when the interior coils are used.

Hybrid EF coils using both the interior and the exterior coils are proposed.28 In this system, the interior currents are permitted to respond to changes in the plasma in a fast time scale and then to decay in a slow time scale. The exterior currents can now respond in the slow time scale. The interior, time-averaged currents are reduced by an order of magnitude below the case when the interior coils are used alone. This permits the use of small, single-turn coils and substantially improves their engineering properties, while the power supply required by the exterior coils can be reduced by an order of magnitude. 


\subsection{MICROWAVE START-UP - REDUCED COST OF OH POWER SUPPLY ${ }^{30}$}

Assuming the benefit of the hybrid EF coils, the power requirement of the $\mathrm{OH}$ coils in TNS is shown to be $\sim 1.4 \mathrm{GW} .28$ The estimated cost of the $\mathrm{OH}$ power supply is between 150-250 M\$. ${ }^{4}$ These large power and cost requirements stem primarily from the high and pulsed loop voltage $\left(\mathrm{V}_{\mathrm{L}}>300 \mathrm{~V}\right.$ for a duration of about $\left.0.2 \mathrm{sec}\right)$ estimated for plasma start-up in full bore. ${ }^{31}$ The value of $V_{L}$ could be reduced if a method can be found to preheat the electrons to a few hundred $\mathrm{eV}$ in a small volume.

The scenario of toroidal plasma start-up with microwave initiation and heating near the upper hybrid frequency is examined. ${ }^{30}$ We assume microwave irradiation in the extraordinary mode from the high field side and large absorptions of the extraordinary wave near the upper hybrid resonance. Electron energy losses are due to magnetic field curvature and parallel drifts, ionization of neutrals, cooling by ions, and radiation by oxygen. It is shown by particle and energy balance considerations that electron temperatures around $250 \mathrm{eV}$ and densities of $10^{12}-10^{13}$ $\mathrm{cm}^{-3}$ can be maintained, at least in a narrow region near the upper - hybrid resonance. The corresponding microwave power requirements are estimated to be $<0.6 \mathrm{MW}$ at a frequency of $120 \mathrm{GHz}$.

The loop voltage and duration required for start-up from this initial plasma in TNS are estimated to be $33 \mathrm{~V}$ and $1.8 \mathrm{sec}$, respectively, to reach a full current of 4.2 MA. These lowered $V_{L}$ and smoothed voltage pulses, each by an order of magnitude from the unassisted start-up, are expected to reduce the $\mathrm{OH}$ power supplies substantially; verification of this start-up method can be carried out in the ISX experiment. 32

\section{CONCLUSION}

The consistent set of reactor plasma parameters exemplified in Table 1 for the TNS tokamak is arrived at based on reasonable fusion physics assumptions. These include the scaling of the plasma density with the heating power, the inclusion of the trapped particle loss rates into 1-D multifluid transport calculations, the FCT nature of the plasma 
evolution during rapid plasma heating, the "she11-like" EF coils appropriate for $D$-shaped high beta plasmas, the latest estimates of $\bar{B}$ limits by the pressure-driven MHD ballooning modes, the coupled equilibrium evolution and transport calculations in a D-shaped FCT, and the centrally localized $\alpha$-particle heating profile that lowers the neutral beam energy requirements.

Our calculations have identified that a D-shaped TNS reactor with medium fields $\left(B_{T}=4-7 \mathrm{~T}\right)$, medium-to-high densities $\left(0.6 \times 10^{14} \mathrm{~cm}^{-3} \leqslant\right.$ $\left.\mathrm{m} \leqslant 2.5 \times 10^{14} \mathrm{~cm}^{-3}\right)$, high betas $(\bar{\beta}$ up to about $10 \%$ ), a major radius of $5 \mathrm{~m}$, a vertical elongation of 1.6 , and an aspect ratio of four, encompasses a viable tokamak reactor concept. We also showed that the ignition and burn process in the TNS reactor can occur over wide ranges of fusion power output and plasma density below the maxima set by the stability $\bar{B}$ limits. This is in contrast to the sharp thresholds in density and power output indicated by the $0-D$ calculations. Although we have used the TNS reactor as a focus, the result of these studies should be equally applicable to the plasma cores in short pulse ignition test reactors and long pulse power demonstration plants.

To further improve the attractiveness of our medium-field reactor concept for TNS, we have derived improved understandings and explored innovative approaches in the plasma engineering studies that have high potentials of reducing the size, cost, and complexity of the reactor. Here we have discussed the examples related to four areas of anticipated technological difficulties: the high fueling pellet velocity, the limited access between the TF coils, the difficulties of building and maintaining large, multiturn EF coils interior to the TF coils, and the large and costly pulsed $\mathrm{OH}$ power supply.

The proposed solutions to these difficulites are expected to impact the TNS reactor in a very beneficial fashion, although detailed engineering evaluations of these innovations are needed to quantify the benefits. Each of these exploratory results for the TNS reactor, if verified by upcoming theoretical and experimental studies, should equally benefit many other tokamaks. 


\section{ACKNOWLEDGMENTS}

This work has benefited from discussions with J. D. Callen, J. R. McNally, Jr., R. A. Dory, M. Roberts, and D. Steiner. 
REFERENCES

1. M. Roberts, W. R. Becraft, C. A. Flanagan, Y-K. M. Peng, and T. C. Var1jen, "Development of TNS Design Space," presented at IAEA Conference and Workshop on Fusion Reactor Design (University of Wisconsin, Madison, October 10-21, 1977).

2. J. F. Clarke and D. G. McAlees, "High Beta Predemonstration Fusion Devices: Philosophy, Characteristics, and R\&D Requirements," ORNL/TM-5692, Oak Ridge National Laboratory, Oak Ridge, Tennessee (November 1976).

3. T. E. Shannon, R. L. Reid, E. S. Bettis, M. B. Baer, C. F. Fisher, Jr., N. E. Johnson, W. D. Jones, W. C. T. Stoddart, and H. L. Watts, "Oak Ridge Tokamak Experimental Power Reactor Study-1976, Part 5 Engineering," ORNL/TM-5576, Oak Ridge National Laboratory, Oak Ridge, Tennessee (February 1977).

4. K. I. Thomassen, H. F. Vogel, D. M. Seldon, W. L. Bird, Jr., M. D. Driga, D. J. Mayha11, F. M. Heck, E. I. King, and R. E. Stillwagon, "Ohmic Heating Systems Study for a Tokamak EPR," LA-UR-77-398 (LASL, February 1977).

5. M. Murakami, J. D. Callen, and L. A. Berry, Nuc1. Fusion 16, 347 (1977).

6. S. 0. Dean et al., "Status and Objectives of Tokamak Systems for Fusion Research," USAEC Report, WASH-1295 (1974).

7. A. T. Mense, S. E. Attenberger, and W. A. Houlberg, "Fueling Profile Sensiclvitiès of Irapped Particle Mode Transport for TNS," to be presented at the American Nuclear Society Winter Meeting (San Francisco, California, November 28-December 2, 1977).

8. J. F. Clarke and D. J. Sigmar, Phys. Rev. Lett. $\underline{38}, 70$ (1977).

9. R. A. Dory and Y-K. M. Peng, Nuc1. Fusion 17, 21 (1977).

10. J. D. Callen, J. F. Clarke, R. A. Dory, J. A. Holmes, F. B. Marcus, D. G. McAlees, J. K. Moore, D. B. Nelson, Y-K. M. Peng, R. O. Sayer, D. J. Sigmar, D. J. Strickler, K. T. Tsang, and N. A. Uckan, "Tokamak Plasma Magnetics," in Plasma Physics and ControlZed Nuclear Fusion Research, Vol. II, p. 369 (IAEA, Vienna, 1977). 
11. G. Bateman and Y-K. M. Peng, Phys. Rev. Lett. 38, 829 (1977).

12. A. Sykes, J. A. Wessen, and S. J. Cox, Phys. Rev. Lett. 39, 757 (1977).

13. J. A. Holmes and Y-K. M. Peng, "Time Dependent Equilibrium Evolution in a Flux-Conserving D-T Tokamak Reactor," Bu11. Am. Phys. Soc. $\underline{22}$, 1135 (1977).

14. J. A. Rome, Y-K. M. Peng, and J. A. Holmes, "Injection Heating Scenarios for TNS," ORNL/TM-5931, Oak Ridge National Laboratory, Oak Ridge, Tennessee (July 1977).

15. L. A. Berry et a1., "Cúnfinemente and Neutrsl Beam Injertion Studies on ORMAK," in Plasma Physics and Controlled Nuclear Fusion Research, Vo1. I, p. 49 (1977).

16. E. Apgar, B. Coppi, A. Gondhalekar, H. Helava, D. Komm, F. Martin, B. Montgomery, D. Pappas, R. Parker, and D. Overskei, "High Density and Collisional Plasma Regimes in the Alcator Program," in Plasma Physics and Controlled Nuclear Fusion Research, Vol. I, p. 247 (IAEA, Vienna, 1977).

17. F. B. Marcus and S. E. $\Lambda$ ttenberger, "Sens1tivity Study of TNS Tokamak Parameters," to be published.

18. J. F. Clarke, "An Improved Estimate of Trapped Ion Mode Energy Loss from Tokamak Reactors," ORNL/TM-5860, Oak RIdge National Laboratory, Oak Ridge, Tennessee (May 1977).

19. A. T. Mense, W. A. Houlberg, S. E. Attenberger, and S. L. Milora, "Effects of Fueling Profiles on Plasma Transport," ORNL/TM-6026 (to be published).

20. Y-K. M. Peng, R. A. Dory, and D, J. Strickler, "Poloidal Field Considerations for D-Shaped Tokamaks," ORNL/TM-5648 (to be published).

21. D. Dobrott, D. B. Nelson, J. M. Greene, A. H. Glasser, M. S. Chance, and E. A. Frieman, Phys. Rev. Lett. 39, 943 (1977).

22. A. M. M. Todd, M. S. Chance, J. M. Greene, R. C. Grimm, J. L. Johnson, and J. Manickam, Phys. Rev. Lett. 38, 826 (1977).

23. Y-K. M. Peng, R. A. Dory, D. B. Nelson, and R. O. Sayer, "Magnetohydrodynamic Equilibria and Local Stability of Axisymmetric Tokamak Plasmas," ORNL/TM-5267, Oak Ridge National Laboratory, Oak Ridge, Tennessee (August 1976); to be published in Phys. Fluids. 
24. W. A. Houlberg, A. T. Mense, and S. E. Attenberger, "Sensitivity of Ignition in TNS to Fueling Profiles and Radial Transport Processes," paper presented at 7 th Symposium on Engineering Problems of Fusion Research, Knoxville, Tennessee, October 25-28, 1977.

25. C. A. Foster, R. J. Colchin, S. L. Milora, J. Kim, and R. J. Turnbull, "Solid Hydrogen Pellet Injection into the ORMAK Tokamak," ORNL/TM-5897, Oak Ridge National Laboratory, Oak Ridge, Tennessee (June 1977).

26. N. A. Uckan et al., "Calculations of Magnetic Field Ripple Effects in Circular and Non-circular Tokamaks," ORNL/TM-5603, Oak Ridge National Laboratory, Oak Ridge, Tennessee (September 1977).

27. N. A. Uckan et al., "Toroidal Field Ripple Effects in the TNS Device," paper presented at 7 th Symposium on Engineering Problems of Fusion Research, Knoxville, Tennessee, October 25-28, 1977.

28. Y-K. M. Peng, D. J. Strickler, and R. A. Dory, "Hybrid Equilibrium Field Coils for the ORNL TNS," paper presented at 7 th Symposium on Engineering Problems of Fusion Research, Knoxville, Tennessee, October 25-28, 1977.

29. G. Becker and K. Lackner, "Axisymetric Instabilities of Non-Circular Plasma Cross Sections and Computation of Highly Elongated Tokamak Equilibria," in Plasma Physics and Controlled Nuclear Fusion Research, Vol. II, p. 401 (IAEA, Vienna, 1977).

30. Y-K. M. Peng and S. K. Borowski, "Microwave Start-up of Tokamak Plasmas Near Electron Cyclotron and Upper Hybrid Resonances," ORNL/TM-6112, Oak Ridge National Laboratory, Oak Ridge, Tennessee, (November 1977).

31. D. G. McAlees, F. B. Marcus, S. E. Attenberger, R. N. Cherdack, G. D. Kerbel, J. R. McNally, Jr., Y-K. M. Peng, G. Schilling, D. J. Strickler, and N. A. Uckan, "Plasma Engineering in a DeuteriumTritium Fueled Tokamak," ORNL/TM-5573, Oak Ridge National Laboratory, Oak Ridge, Tennessee (October 1976). 
32. A. C. England, 0. C. Eldridge, F. B. Marcus, J. C. Sprott, W. Namkung, and J. B. Wilgen, "High Power Electron Cyclotron Heating in ISX and ORMAK Upgrade at ORNL," ORNL/TM-5452, Oak Ridge National Laboratory, Oak Ridge, Tennessee (May 1976). 
INTERNAL DISTRIBUTION

ORNL/TM-6150

1. L. A. Berry

2. J. D. Callen

3. R. A. Dory

4. G. G. Kelley

5. 0. B. Morgan

6. M. W. Rosenthal

7-31. Y-K. M. Peng

32-34. Laboratory Records Department

35. Laboratory Records, ORNL - RC

36. Y-12 Document Reference Section

37-38. Central Research Library

39. Fusion Energy Division Library

40. Fusion Energy Division Reports Office

41. ORNL Patent Office

\section{EXTERNAL DISTRIBUTION}

42. Plasma Physics Library, Plasma Physics Laboratory, Princeton Univ., Forrestal Campus, P.0. Box 451, Princeton, NJ 08540

43. Controlled Thermonuclear Research Library, Lawrence Livermore Laboratory, P.0. Box 808, Livermore, CA 94550

44. Q Division Library, Los Alamos Scientific Laboratory, P.0. Box 1663, Los Alamos, NM 87544

45. Controlled Thermonuclear Research Library, c/o Weston M. Stacey, Jr., Argonne National Laboratory, 9700 S. Cass Ave., Argonne, IL 60439

46. CTR Computer Center, c/o Dr. John Killeen, Lawrence Livermore Laboratory, P.0. Box 808, Livermore, CA 94550

47. Librarian, Culham Laboratory, U.K. Atomic Energy Authority, Abingdon, Oxon, OX14 3DB, United Kingdom

48. Ruth Lengye, Bibliothek, Max-Planck Institut für Plasmaphysik, 8046 Garching bei München, Federal Republic of Germany

49. Library, Centre de Recherches en Physique des Plasmas, 21 Avenue des Bains, 1007, Lausanne, Switzerland

50. A. M. Dupas, Documentation S.I.G.N., Départment de la Physique du Plasma et de la Fusion Controlée, Assoclation EURATOM-CEA sur 1a Fusion, Centre d'Etudes Nucléaires, BP 85 Centre Du TRI 38041 Grenoble Cedex (France)

51. Blbllothèque, Service du Confinement des Plasmas, C.E.A., B.P. No. 6, 92, Fontenay-aux-Roses (Seine) France

52. Library, International Centre for Theoretical Physics, Trieste, Italy

53. Library, Laboratorio Gas Ionizzati, Frascati, Italy

54. V. E. Ivanov, Physica1-Technical Institute of the Ukranian Academy of Sciences, Sukhumi, U.S.S.R.

55. L. M. Kovrizhnikh, Lebedev Institute of Physics, Academy of Sciences of the U.S.S.R., Leninsky Prospect 53, Moscow, U.S.S.R.

56. Prof. Dshumber G. Lominadze; Academy of Sciences of the Georgian SSR, 8 Dzerzhinski St., 38004, Tbilisi, U.S.S.R.

57. Library, Inst. for Plasma Physics, Nagoya Univ., Nagoya, Japan 464 
58. Library, FOM-Institut voor Plasma-Fysica, Rijnhuizen, Jutphaas, Netherlands

59. Plasma Physics Group, Department of Engineering Physics, Australian National University, P.0. Box 4, Canberra A.C.T. 2600, Australia

60. Thermonuclear Library, Japan Atomic Energy Research Institute, Tokai, Naka, Ibaraki, Japan

61. Dr. D. G. McAlees, Exxon Nuclear Co., Inc., Research \& Technology Laser Enrichment Department, 2955 George Washington Way, Richland, WA 99352

62. CTR Reading Room, c/o Prof. D. W. Kerst, Dept. of Physics, Sterling Ha11, Univ. of Wisconsin, Madison, WI 53706

63. CTR Reading Room, c/o Prof. I. B. Bernstein, Yale Univ,, 200 Mason Laboratory, Dept. of Engineering \& Applied Science, New Haven, CT 06510

64. Center for Plasma Yhysics and Thermonuclear Research, c/o D. W. Ross, Physics Dept., Univ. of Texas, Austin, TX 78712

63. CTR Readlug Ruum, c/u Trof. B. D. Fricd, Phyoics Dept., Unisy, of California, Los Angeles, CA 90024

66. CTR Reading Room, c/o Prof. David C. Montgomery, Physics \& Astronomy Dept., Univ. of Iowa, Iowa City, IA 52240

67. Magneto-Fluid-Dynamics Library, c/o Dr. Harold Grad, Courant Inst. of Math. Sci., New York Univ., 251 Mercer St., New York, NY 10012

68. CTR Reading Room, c/o Prof. Allan N. Kaufman, Physics Dept., Univ. of California, Berkeley, CA 94720

69. Dr. David A. Dingee, Fusion Programs, Battelle-Northwest, Battelle Boulevard, Richland, WA 99352

70. CTR Reading Room, c/o Prof. C. S. Liu, Dept. of Physics and Astronomy, Univ. of Maryland, College Park, MD 20742

71. CTR Reading Room, c/o Prof. T: Kammash, 103 Research Admin. B1dg., N. Campus, Untv, of M1ch1gan, Ann Arbor, MI 48105

72. CTR Reading Room, c/o Dr. Ravl N. Sudan, Phillips Hall, Cornell Univ., Ithaca, NY 14850

73. Prof. Marshall N. Rosenbluth, Institute for Advanced Study, Princeton, NJ 08540

74. CTR Reading Room, c/o Prof. R. Gross, Plasma Research Lab., Columbia Univ., New York, NY 10027

75. CTR Reading Room, c/o Prof. Roy Gould, California Inst. of Tech., M.S. 116-81, Pasadena, CA 91125

76. Dr. Nicholas A. Kral1, Science Applications, Inc., P.0. Box 2354, 1200 Prospect St., La Jolla, CA 92037

77. CTR Reading Room, c/o Dr. Jay P. Boris, Plasma Physics, Naval Research Laburatory, Washington, D.C. 20390

78. Professor A. Simon, Dept. of Mechanical \& Aerospace Sciences, University of Rochester, Rochester, NY 14627

79. CTR Library, c/o Dr. Alan F. Haught, United Technologies Research Labs, East Hartford, CT 06108

80. Dr. H. K. Forsen, Exxon Nuclear Co., Inc., 777-106th Avenue, NE, C-000777, Bellevue, WA 98009

81. Dr. George Vahala, Physics Dept.; College of William \& Mary, Williamsburg, VA 23185

82. Dr. Robert E. Price, Division of Magnetic Fusion Energy, G-234, Department of Energy, Washington, D.C. 20545 
83. Dr. R. C. Davidson, Division of Magnetic Fusion Energy, G-234 Department of Energy, Washington, D.C. 20545

84. Dr. Oscar P. Manley, Division of Magnetic Fusion Energy, G-234, Department of Energy, Washington, D.C. 20545

85. Mr. E. E. Kintner, Division of Magnetic Fusion Energy, G-234, Department of Energy, Washington, D.C. 20545

86. Dr. L. D. Pearlstein, L-388, Lawrence Livermore Laboratory, P.0. Box 808, Livermore, CA 94550

87. Dr. J. P. Friedberg, Los Alamos Scientific Laboratory, Los Alamos, NM 87544

88. Dr. David J. Rose, Dept. of Nuclear Engineering, MIT, Cambridge, MA 02139

89. Dr. Gareth E. Guest, General Atomic Co., P.0. Box 81608, San Diego, CA 92138

90. Dr. Claude Mercier, Service du Theorie des Plasmas, Centre d'Etudes Nucléaires, Fontenay-aux-Roses (Seine) France

91. Dr. J. B. Taylor, Culham Laboratory, UKAEA, Abingdon, Oxon, ox14 3DB, United Kingdom

92. Dr. D. Pfirsch, Institute for Plasma Physics, 8046 Garching bei München, Federal Republic of Germany

93. Dr. V. D. Shafranov, I. V. Kurchatov Inst. of Atomic Energy, 46 Ulitsa Kurchatova, P.O. Box 3402, Moscow, U.S.S.R.

94. Dr. A. Rogister, Institute for Plasma Physics, KFA, Postfach 1913, D-5170, Jülich 1, Federal Republic of Germany

95. Dr. J. G. Cordey, Culham Laboratory, UKAEA, Abingdon, Oxon, OX14 3DB, United Kingdom

96. Dr. David Baldwin, L-388, Lawrence Livermore Lab., P.0. Box 808, Livermore, CA 94550

97. CTR Reading Room, c/o Prof. Bruno Coppi, Dept. of Physics, MIT, Cambridge, MA 02138

98. Dr. Harold P. Furth; Princeton Plasma Physics Lab., Princeton Univ., P.0. Box 451, Princeton, NJ 08540

99. Dr. Paul H. Rutherford, Princeton Plasma Physics Lab., Princeton Univ., P.0. Box 451, Princeton, NJ 08540

100. Research \& Technical Support Div., Oak Ridge Operations, Department of Energy, P.O. Box E, Oak. Ridge, TN 37830

101-127. Tech. Information Center, P.0. Box 62, Oak Ridge, TN 37830 